movement and theories of time are treated. The rest of the volume is taken up by important medieval discussions on the latitudes of forms : before Oresme, in his works and those of his followers, and at the University of Oxford.

Of course, the new volume again displays all the brilliant qualities of style and composition characteristic of Duhem's writings. One cannot help, however, deploring earnestly that such a long time should have passed since his first publications on the subject in Vol. 3 of the "Etudes sur Léonard de Vinci" (1913). In the course of more than forty intervening years much important new material on medieval science has been discovered, and many articles and books on it have appeared. In almost all of these some of Duhem's views have been subjected to severe criticisms or at least have been shown to be in need of modification. The reader of the present posthumous volume has to realize that results obtained after the death of the author could not possibly have been taken into account, but this consideration will not prevent him from wondering at pages which could not have been written in our days by a competent author. Indeed, they belong already to the history of the history of science. It is to be feared that in the eye of an inattentive reader they will derogate from Duhem's everlasting and incontestable merits.

\section{E. J. DiJKsTerHuis}

\section{RANK AND POWER IN THE SOLOMON ISLANDS}

\section{A Solomon Island Society}

Kinship and Leadership Among the Siuai of Bougainville. By Prof. Douglas L. Oliver. Pp. xxii +534+ 16 plates. (Cambridge, Mass. : Harvard University Press; London: Oxford University Press, 1955.) 80s. net.

7 HIS work is a descriptive and analytical record of two years field research on an island in the Western Solomons in the Australian Trust Territory of New Guinea. The term Siuai, originally applied to a cape on the south coast of Bougainville Island, was later applied to a village there and finally has come to be regarded as the name for a large area and for the native people living there. These people, numbering nearly five thousand, are agriculturists living in hamlet clearings in the rough forest on a heavily watered plain. Their staple crops are taro and sweet potato, with coconut, breadfruit and bananas as important ancillaries. As with most Melanesians, the simplicity of their economy is not matched in their social life, which has much of a spectacular, even dramatic, quality.

The book begins with a description of the physical adaptation of the Siuai people to their environment, and of their beliefs and myths about themselves and their universe. One difficulty mentioned by the author at the outset is in relating the categorization of their universe to the categories of their language. For example, the Motuna language which the Siuai people speak has at least forty 'noun classes', the nouns of each class being distinguished by the use of a separate set of numerical adjectives. Though cautious in his view, the author suggests that the differences of quality expressed by special grammatical usages for small round things like nuts and eggs, or long thin things like cord, or flat thin things like leaves, do represent something basic in the way in which the Siuai look at the world around them. But he does not feel able to pursue this relation of language to logic. Of natural science the Siuai have little beyond a crude empiricism. While they are careful agriculturists, cognizant of a large number of entities in the natural world around them, they have not troubled to fit these into any neatly ordered system of beliefs. They are incurious about the size, shape and nature of the Earth, they have some bizarre fancies about the physiology of reproduction, and they use magical rather than medical remedies for curing their ills. Yet they regard industry as a prime virtue-while being humanly inconsistent enough to look on paradise as a place where no one has to work - and they attribute great importance to ambition and renown.

But while their industry gives them a good living, like their ambition it is mainly significant in a social field. The author's analysis here reveals with subtlety the various types of social units and social ties which are relevant in work and striving for renown. The constitution of hamlet and household, the cycle of development of the nuclear family, the structure of primary and secondary kin relations, the organization of production teams and other associations are all examined and in particular the great importance of matrilineal kin units is emphasized. The section on leadership is a most useful one, of direct value to those interested in a practical as well as a theoretical understanding of native affairs in the western Pacific. The facts given are not novel- -on the accumulation of capital in food, pigs and shell 'money', and the role of wealth in building up prestige and power through competitive feasting and display-but the treatment of the facts is fresh and stimulating. The rewards, burdens and social effects of leadership in such a community are made clear, and we are given one of the best accounts of 'social climbing' in a Pacific society that has yet appeared. Once again, too, the radical difference between the governmentappointed native official and the local leader is made plain.

The author's primary aim has been to produce a single-volume account of all the main aspects of Siuai culture, a task which ho has thought necessary in contrast to the dispersed ethnography on most of the other standard cultures studied by the anthropologist. He has amply succeeded in this lively, original, ethnographic account. The final section on generalizations, conjectures and questions is a stimulating set of reflexions of wide theoretical value. RAYMOND Firth

\section{STAINING TECHNIQUES}

\section{A Practical Manual of Medical and Biological Stain- ing Techniques}

By Ldward Gurr. Second edition. Pp. xxv +451 . (London: Leonard Hill (Books), Ltd., 1956.)

THE fact that a second edition of this book has been made necessary within the comparatively short space of time since the first edition appeared is evidence enough of its utility and popularity with the many workers concerned with micro-technique as applied to biological material. 'This edition is considerably enlarged and incorporates many new particulars which have come to hand since 1953. A 